\title{
Solidification and Stabilization of Asbestos Brake Lining Dust Using Polymeric Resins
}

\author{
Y. M. Chan, ${ }^{1}$ P. Agamuthu, ${ }^{1 *}$ and R. Mahalingam ${ }^{2 \dagger}$ \\ ${ }^{1}$ Institute of Postgraduate Studies and Research \\ University of Malaya \\ 50603 Kuala Lumpur, Malaysia \\ ${ }^{2}$ Department of Chemical Engineering \\ Washington State University \\ Pullman, WA 99164-2710
}

\begin{abstract}
Two polymeric resins, Polymal and Hetron, were evaluated to solidify/stabilize (S/S) for ultimate disposal brake lining dust containing asbestos. This dust was generated as part of a sequence of processing steps in the manufacture of automobile brake linings. The mean grain size of the lining dust for disposal was $298.2 \mu \mathrm{m}$, the range being from 24.9 to $567.3 \mu \mathrm{m}$. Based on the Toxicity Characteristic Leachability Procedure (TCLP) and the American Nuclear Society (ANS) 16.1 (modified) leach protocols, although the untreated lining dust contained high concentrations of $\mathrm{Zn}, \mathrm{Ba}, \mathrm{Pb}, \mathrm{Fe}, \mathrm{Cu}$, and $\mathrm{Cr}$, solidification with Polymal and Hetron respectively reduced the leachable fraction of these heavy metals in the lining dust to less than 14 and $18 \%$, compared to untreated control; and the heavy metal concentrations in the TCLP leachate were below the permissible limits set by the Malaysia Environmental Quality Act (EQA) (1974), the Environment Quality (Sewage and Industrial Effluents) Regulations (1979), as well as the USEPA regulatory limit for TCLP. The final $\mathrm{pH}$ of the extract from the untreated dust ranged from 4.92 to 4.95 , whereas when polymeric resins were used, the $\mathrm{pH}$ increased to between 5.1 and 5.2. When the ANS 16.1 (modified) leach test was performed, the leaching rate was highest for $\mathrm{Zn}$, followed by $\mathrm{Ba}$ and $\mathrm{Pb}$, while the leaching of $\mathrm{Cr}, \mathrm{Cu}$, and $\mathrm{Fe}$ was too low for detection. The observed linear relationship between the cumulative fraction leached (CFL) and the square root of the leaching time in all polymer resin treated samples indicates that the mechanism of leaching is mainly through diffusion. The Leachability Index $\left(L_{i}\right)$ obtained ranged between 9 and 10, which exceeds the guidance value of 6 , clearly indicating that the heavy metal retention within the solidified matrix is quite effective. The hardening time when polymeric resins were used ranged anywhere from 1.5 to $12 \mathrm{~h}$, and this decreased as the amount of MEK Peroxide initiator was increased. Compressive strength of the brake lining solid matrix was between 53 and $68 \mathrm{MPa}$, which was much higher than the standard guidance limit for polymeric resin solidification. Between the two resins, Polymal shows better performance in terms of heavy metal retention capability, whereas Hetron exhibits higher compressive strength. Despite the attractive performance features of either of the resins,
\end{abstract}

\footnotetext{
*Corresponding author: Institute of Postgraduate Studies and Research, University of Malaya, 50603 Kuala Lumpur, Malaysia. Phone: 60-3-7594412; Fax: 60-3-7594412;E-mail: h1aga@umcsd.um.edumy

$\dagger$ Fulbright Visiting Professor, IPSR, University of Malaya
} 
S/S with either of them appears to be prohibitively expensive for the current Malaysian regulatory marketplace, although attractive elsewhere.

Key words: solidification; stabilization; asbestos brake lining dust; polymeric resins; Toxicity Characteristics Leachability Procedure (TCLP); American Nuclear Society (ANS 16.1) Leach Procedure; Cumulative Fraction Leached (CFL); Leachability Index $\left(L_{i}\right)$; compressive strength

\section{INTRODUCTION}

D on Brake (Malaysia) Private Limited is a smallmedium industry (SMI) involved in the upstream and downstream production of friction materials for automobiles, buses, and trucks. In 1997, the production of brake lining was $1 / 2$ million pieces, which generated revenue of RM24 million (US\$6.32 million). Other products that year included 3.77 million pieces of brake disc pads, 201,000 pieces of bonded shoes and 133,000 pieces of shoe lining.

The brake lining dust, which is generated during the manufacture of brake linings, particularly during cutting, grinding, drilling, and chamfering of the brake linings, forms the main process waste in this industry (Chan et $a l ., 2000$ a). Brake lining dust constitutes $60 \%$ of the total waste generated, which was approximately 583 metric tons in 1997. Under current management practice, the brake lining dust is packed in double-layered high-density polyethylene (HPDE) plastic bags and placed into 200-L metal drums. The drums are sealed, labeled, and disposed of at the secure landfill at Bukit Nanas Integrated Waste Management Center. The annual cost of disposal is about RM283,000 (US\$75,000), which includes the cost of transportation.

The composition of the waste generated is closely related to the type of raw materials used in the brake lining manufacturing process such as asbestos, iron powder, friction dust, glass fiber, and resin, and $16 \%$ (wt.) of the raw materials used is lost as lining dust. The asbestoscontaining friction materials include brake lining materials in roll, strip, or sheet form, brake blocks and liners, brake lining segments, disc brake pads, clutch facings, automobile transmission discs, and band liners.

Asbestos has been used in friction materials from less than $10 \%$ (wt.) in railroad brake shoes, to over $60 \%$ in some passenger car drum brake lining segments. The main reason for its ban in many countries is based on health implications, linking it to asbestosis, mesothelioma, and bronchogenic carcinoma (Manjunath and Cheremisinoff, 1995).

Solidification/stabilization (S/S) technologies have been widely used in waste treatment for a wide variety of hazardous and mixed waste materials, such as spent pickle liquor, industrial sludge, filtered cakes, contaminated ashes, and soils. S/S reduces the mobility of pollutants, thereby making the waste acceptable under current land-disposal requirements (Wiles, 1989); and sometimes it could be applied to "delist" a waste as hazardous under the Resource Recovery and Reauthorization Act (RCRA) (Means et al., 1995; U.S. EPA Engineering Bulletin, 1992, 1997). The technique is often chosen for wastes with poor handling characteristics (e.g., dusts, viscous sludges) or for a large volume of wastes that are difficult to treat using other technologies (e.g., power plant desulfurization sludges, nuclear industry debris). It is also used when chemical detoxification of a hazardous waste stream is either not technically applicable or prohibitively expensive (Powell and Mahalingam, 1992a, 1992b). S/S methods are designed to accomplish one or more of the following objectives (Wiles, 1989; Means et al., 1995; U.S. EPA Engineering Bulletin, 1997): (1) improve material handling by forming a monolith, (2) reduce the hazardous constituents' solubility, (3) decrease the exposed surface area and porosity of the waste, and (4) reduce permeability.

Polymer encapsulation is a relatively new technology (Powell and Mahalingam, 1992a, 1992b). Polymers with their rapid setting, high strength, and elasticity, high impermeability and high corrosive resistance appear to be an effective means of reducing leachability of solidified/stabilized waste matrix prior to disposal into landfill. The hydrophobic system after curing tends to resist leaching even if crushed to small particle size with leaching limited to parts per billion (ppb) range (Conner, 1990). It is particularly well suited to treat water-soluble salts such as chlorides and sulfates that generally are difficult to immobilize in a cement-based system (U.S. EPA/ORIA, 1996; U.S. EPA Engineering Bulletin, 1997). Two classes of polymers, thermoplastic and thermosetting, are commonly applied for encapsulation.

Polymeric encapsulation has been successfully used to solidify low-level radioactive wastes and a wide spectrum of toxic chemical wastes such as arsenic, cyanide, PCB, toxic metals, and pharmaceutical wastes (Subramaniam and Mahalingam, 1979). Kim et al. (1992) have solidified borate waste using polyester to produce a high integrity monolith with very low diffusion coefficient. 
Breslin and Tisdell (1994) used high-density polyethylene and polystyrene resins to retard the leaching of metals and salts associated with combustor ash.

A wide range of performance tests may be used in conjunction with $\mathrm{S} / \mathrm{S}$ treatability studies to evaluate shortand long-term stability of the solidified matrix. These include total waste analysis for organics, leachability studies using various protocols, permeability testing, unconfined compressive strength (UCS), treated waste, and/or leachate toxicity end points and durability test (freeze/ thaw and wet/dry weathering cycle tests) (LaGrega et al., 1994; Means et al., 1995). In addition, Grube (1992) described the application of physical and morphological measures to help determine the effectiveness of S/S technologies through laboratory testing, observation, and analysis of visible characteristics.

Leach testing has been recognized as the primary and most widely used indicator for evaluating the retention capacity of solidified/stabilized waste mass. However, the leach test should simulate the actual environment conditions in the disposal site (Albino et al., 1996), but no single leach testing procedure or protocol can duplicate all possible field conditions. Many leaching tests have been described (Conner, 1990; LaGrega et al., 1994; Means et al., 1995), and these tests could be broadly classified as (1) extraction tests, (2) leach tests, and (3) column leach tests. Extraction tests, such as the Toxicity Characteristics Leaching Procedure (TCLP) and Extraction Procedure (EP) Toxicity Tests, involve agitation of ground/pulverized wastes (particles size less than 9.5 $\mathrm{mm}$ ) in a leachant to achieve uniform mixing, for a specified period. The resulting leachate is analyzed for heavy metals and other constituents leached. Leach testing involves no agitation of monolithic waste mass, and could be carried out either at a static condition (without replacing the leachant) or at semidynamic leaching conditions (leachant is replaced at specified intervals) such as in an American Nuclear Society leach test (ANSI/ANS 16.1). The ANSI/ANS 16.1 developed a figure of merit (Leachability Index) for comparing the leaching resistance of S/S-treated waste and also to indicate contaminant release rate. Column leach tests involve placing pulverized waste in a column where it continuously contacts a leaching solution at a predetermined rate (Sharma and Lewis, 1994).

There is a wealth of information on the use of asbestos and the health implications. However, there is hardly any information on the S/S treatment of brake lining waste containing asbestos. Hence, this study is focused on solidification/stabilization of the brake lining dust using two polymeric resins as an alternate treatment and disposal option instead of direct landfilling into secure landfills. The effectiveness of the S/S technique used is eval- uated using leaching tests that include: (1) extraction tests (Toxicity Characteristics Leaching Procedure, TCLP) and (2) leach tests (American Nuclear Society Leach Test, ANSI/ANS 16.1 modified). Hardening time and compressive strength of the hardened matrix are also investigated.

\section{MATERIALS AND METHODS}

\section{Collection of samples}

The brake lining dust, which is powdery gray, was obtained from Don Brake (M) P. Ltd. A Laser Diffraction Particle Size Analyzer (Coulter, Miami, FL) was used to analyze the particle size distribution of the dust prior to solidification.

\section{Polymeric resins}

Resins used were (a) Polymal 820 (an orthophthalic ester) and (b) Hetron 922 (a vinyl ester). Polymal 820 was produced by Takeda Chemical Industries, Japan, whereas Hetron was obtained from Ashland Chemical Co., Columbus, $\mathrm{OH}$. The resins were prepromoted to facilitate room temperature curing. Methyl Ethyl Ketone (MEK) Peroxide was used as the solidification initiator. Physical properties of the two resins are summarized in Table 1.

\section{Polymeric encapsulation}

Preliminary trials were carried out to determine both the resin-to-waste loading range and the corresponding initiator requirement, to ensure resin hardening was accomplished within a reasonable time $(24 \mathrm{~h})$; the control samples were the ones without brake lining dust. Test samples were prepared by mixing a predetermined amount of initiator at room temperature into a batch of resin, and the brake lining dust was then added to the ini-

Table 1. Physical data for the two polymeric resins used.

\begin{tabular}{lcc}
\hline Resin properties & $\begin{array}{c}\text { Polymal } \\
820^{\mathrm{a}}\end{array}$ & $\begin{array}{c}\text { Hetron } \\
922^{\mathrm{b}}\end{array}$ \\
\hline Resin type & Orthophthalic & Vinyl Ester \\
Viscosity, cps & $370-470$ & 450 \\
Tensile strength, psi & 11,000 & 12,500 \\
Gel time, minutes & $10-30$ & $12-20$ \\
Specific gravity, $\mathrm{kg} / \mathrm{m}^{3}$ & $1.05^{\mathrm{c}}$ & $1.10^{\mathrm{c}}$ \\
Peak exotherm, ${ }^{\circ} \mathrm{C}$ & 120 & 187.6 \\
\hline
\end{tabular}

aTakeda Chemical Industries.

b Ashland Chemical Co., Columbus, $\mathrm{OH}$.

${ }^{\mathrm{c}}$ Determined in this study. 
tiated resin. The contents were mixed thoroughly for 2-3 min to obtain rapid and even distribution of the dust throughout the mixture. The resulting mixture was transferred to specified molds, hand compacted, and left for solidification. Three different resin loadings were prepared $(60,50$, and $45 \%$ wt.) for the detailed studies; also, below a resin loading of $40 \%$, the added dust occasionally agglomerated, and complete wetting of dust was difficult. Methyl Ethyl Ketone (MEK) Peroxide was used as the initiator, at 3 and 5\% (wt.) based on the resin.

\section{Leach tests}

Toxicity Characteristics Leaching Procedure (TCLP). TCLP Protocol (U.S. EPA method 1311, 1992) was performed using the samples that were crushed to particle size smaller than $9.5 \mathrm{~mm}$ and transferred to flasks. A buffer of acetic acid and sodium hydroxide adjusted to $\mathrm{pH} 4.93 \pm 0.05$ was used as the appropriate extraction fluid. A liquid-to-solid ratio of 20:1 was used. The flasks were then covered with parafilm, capped with aluminum foil, and then mechanically shaken for $18 \mathrm{~h}$ continuously at $300 \mathrm{rpm}$ and temperature set at $25 \pm 2^{\circ} \mathrm{C}$ to allow for complete reaction.

After $18 \mathrm{~h}$ contact time, the leachates were filtered through a $0.8-\mu \mathrm{m}$ pore size borosilicate glass fiber filter to separate the solid and liquid phases. The filtrate, i.e., the TCLP extract, was tested for $\mathrm{pH}$ using a Hanna Instrument Membrane pH Meter. Heavy metals in the TCLP extract were analyzed using Inductively Couple Plasma-Emission Spectroscopy (ICP-AES, Baird Model 2000). The results of this extraction test are expressed in terms of the percentage of leachable fraction $f$, for each element, which is defined as the amount of a particular heavy metal extracted relative to the amount originally present in untreated dust (Brodersen et al, 1992).

American Nuclear Society [ANSI/ANS 16.1 (modified)]. Solidified specimens of thickness-to-diameter ratio 0.3 were suspended into the leachant (ultrapure water of resistivity $=18 \mathrm{Mohm}-\mathrm{cm}$, processed by ELGAS$\mathrm{TAT}^{\mathrm{R}}$ UHQPS) using a nylon fishing line. The leachant was contained in plastic beakers made of nonreactive polypropylene. Neither the beaker nor the fishing line contributed to the concentration of heavy metals in the leachate. The ratio of the leachant volume $\left(\mathrm{cm}^{3}\right)$ to the external geometry surface area $\left(\mathrm{cm}^{2}\right)$ of the solid specimen was maintained at about $10 \pm 0.2(\mathrm{~cm})$ throughout the static leaching procedure (American Nuclear Society (ANS), 1986). The leaching was carried out over a 28 day period as follows (i.e., not over the 90 -day period as is normally done for low-level radioactive wastes): the specimen was transferred into fresh leachant after 1, 2,
4, 7, and 14 days; next, the leachate samples from the $1 \mathrm{st}, 3 \mathrm{rd}, 7 \mathrm{th}, 14 \mathrm{th}$, and 28th days were analyzed for $\mathrm{pH}$ and heavy metals, as was the case for the TCLP leachate samples.

Data obtained from this ANS 16.1 (modified) method was recorded in terms of Leaching Rate $(l)$ and Cumulative Fraction Leached (CFL) relative to the total mass in the waste sample. Subsequently, from these calculations, the Effective Diffusivity $(D)$ and Leachability Index $\left(L_{i}\right)$ were also obtained (ANS, 1986; Kim et al., 1992):

1. Leaching rate, $l_{n}(\mathrm{~cm} /$ day), for the $n$th interval is

$$
l_{n}=\frac{a_{n}}{A_{o}} \times \frac{V}{S} \times \frac{1}{\Delta t_{n}}
$$

where $a_{n}$ is the amount of constituent or heavy metal of interest leached from the specimen during the $n$th interval $(\mathrm{mg}) ; A_{o}$ is the amount of constituent of interest initially present in the specimen $(\mathrm{mg}) ; a_{n} / A_{o}$ is the incremental fraction leached; $V / S$ is the ratio of specimen volume to surface area $(\mathrm{cm}) ; \Delta t_{n}$ is the $t_{n}-t_{n-1}$, duration of the $n$th leaching interval (days or seconds, as appropriate), and $t_{n}$ is the $\Sigma \Delta t_{n}$, cumulative leaching time since the beginning of the first leaching interval (days or seconds, as appropriate).

2. Cumulative fraction leached, CFL $(\mathrm{cm})$, is

$$
\mathrm{CFL}=\frac{\Sigma}{A_{o}} \times \frac{V}{S}
$$

3. Effective diffusivity, $D\left(\mathrm{~cm}^{2} / \mathrm{s}\right)$, is a measure of the diffusivity of each of the heavy metals of concern in the monolithic specimen of solidified/stabilized waste for each leaching interval.

$$
D=\left[\frac{a_{n} /}{\Delta} \frac{A_{o}}{t_{n}}\right]^{2}\left[\frac{V}{S}\right]^{2} T
$$

where $T$, the leaching time representing the "mean time" of the $n$th leaching interval (seconds), is given by

$$
T=\left[\frac{1}{2}\left(t_{n}^{1 / 2}+t_{n-1}^{1 / 2}\right)\right]^{2}
$$

4. Leachability Index, $L_{i}$ (dimensionless), gives a measure of the effectiveness of the S/S technique for the control of leaching. It is defined as a material parameter that characterizes the resistance of the solidified waste to leaching of the constituents. Larger values of $L_{i}$ imply smaller values for the contaminant diffusing out (i.e., a lower value for contaminant release rate) (Morgan and Bostick, 1992).

$$
L_{i}=\frac{1}{n} \sum\left[\log \left(\frac{\beta}{D_{i}}\right)\right]_{n}
$$


where $\beta$ is a defined constant $\left(1.0 \mathrm{~cm}^{2} / \mathrm{s}\right), n$ is the number of leach intervals, and $D_{i}$ is the effective diffusivity of constituent $i\left(\mathrm{~cm}^{2} / \mathrm{s}\right)$.

\section{Physical testing}

Hardening time. Hardening time was recorded based on visual observation and hand pressing the specimen.

\section{Compressive strength test}

Specimens for compressive strength test were prepared according to the American Standard Testing Material (ASTM, 1992) Test Method for Compressive Strength of Hydraulic Cement Mortars (using 2-inch or 50-mm cube specimens) C109/c 109M-95 testing protocols. Compressive strength measurements were performed on the cube specimens in duplicate at the 1st, 7th, 14th, and 28th days of curing (at $98 \% \mathrm{RH}$, temperature $30 \pm 3^{\circ} \mathrm{C}$ ) using a calibrated hand-operated hydraulic compression apparatus (model ELE). Total maximum loads were recorded at the point of fracture, and the compressive strength was calculated as follows:

$$
f_{m}=\frac{P}{A}
$$

where $f_{m}$ is the compressive strength in psi or Mpa; $P$ is the total maximum load in lbf or $N$, and $A$ is the area of loaded surface in inch ${ }^{2}$ or $\mathrm{mm}^{2}$.

\section{RESULTS AND DISCUSSION}

The estimated average grain size of the brake lining dust is $298.2 \mu \mathrm{m}$, the grain size ranging from 24.98 to $567.3 \mu \mathrm{m}$.

\section{TCLP results}

As shown in Table 2, TCLP extract of the untreated brake lining dust contains the highest concentration of $\mathrm{Zn}$, followed by $\mathrm{Ba}, \mathrm{Pb}, \mathrm{Fe}, \mathrm{Cu}$, and $\mathrm{Cr}$, the concentrations ranging between 0.18 to $5.9 \mathrm{mg} / \mathrm{L}$. Among these heavy metals, the concentration of $\mathrm{Zn}, \mathrm{Pb}$, and $\mathrm{Cr}$ exceeded the regulatory limit stipulated in Malaysia Environmental Quality (Sewage and Industrial Effluents, 1979), Standard B, which is for effluent release downstream of the source of water intake. However, the metals $\mathrm{Ba}, \mathrm{Cr}$, and $\mathrm{Pb}$ were within the permitted level for the TCLP test, while the regulatory limit for $\mathrm{Zn}, \mathrm{Cu}$, and $\mathrm{Fe}$ were not available. Solidification with Polymal and Hetron reduced all the elements investigated to within the Malaysia EQA (1974) limit. Ba concentration in Poly-

Table 2. Summary of TCLP leach data, including initial and final $\mathrm{pH}$ of the extract.

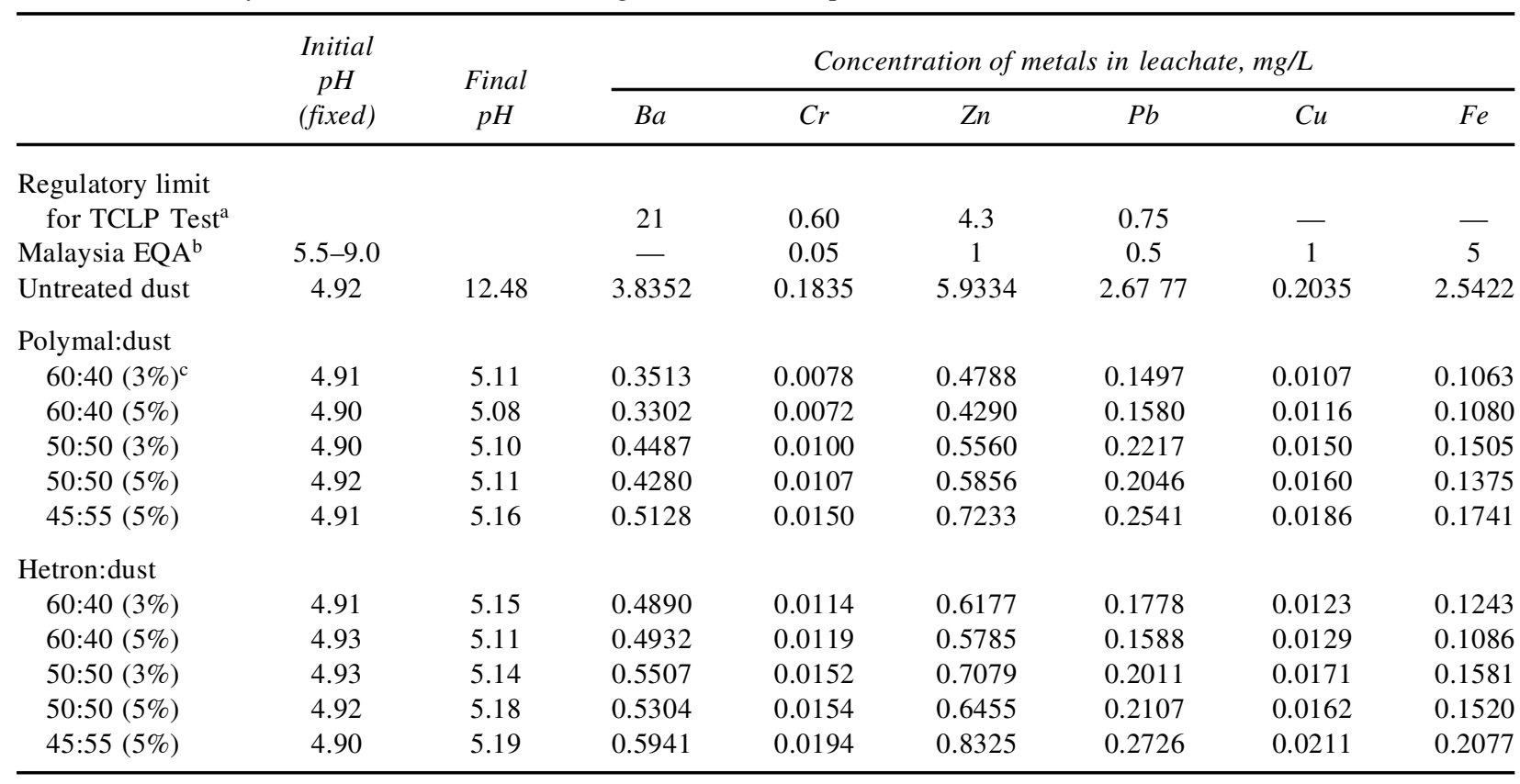

${ }^{\text {a} F e d e r a l ~ R e g i s t e r ~ 63, ~ N o . ~ 100, ~ M a y ~ 26, ~} 1998$.

${ }^{\mathrm{b}}$ Regulatory limit stipulated in Malaysia Environmental Quality Act 1974, Environmental Quality (Sewage and Industrial Effluents) Regulations, 1979, StandardB.

${ }^{\mathrm{c}}$ Quantity in parentheses: wt.\% MEK peroxide initiator used based on wt. of resin. 
mal-treated TCLP leachate ranged between 0.33 and 0.51 $\mathrm{mg} / \mathrm{L}$, whereas it was between 0.49 and $0.59 \mathrm{mg} / \mathrm{L}$ in Hetron-treated TCLP leachate. The U.S. EPA regulatory limit for $\mathrm{Ba}$ is $100 \mathrm{mg} / \mathrm{L}$ (Table 2). Similarly, for $\mathrm{Cr}$ and $\mathrm{Cu}(0.05$ and $1.0 \mathrm{mg} / \mathrm{L}$, respectively), it was reduced to below $0.02 \mathrm{mg} / \mathrm{L}$.

Polymal reduced the percentage of leachable fraction, $f$, of all the heavy metals of concern to less than $14 \%$, where the leachable fraction ranged between $8.6-13.4 \%$ for $\mathrm{Ba}, 3.95-8.2 \%$ for $\mathrm{Cr}, 7.2-12.2 \%$ for $\mathrm{Zn}, 5.6-9.5 \%$ for $\mathrm{Pb}, 5.3-9.1 \%$ for $\mathrm{Cu}$, and $4.2-6.9 \%$ for $\mathrm{Fe}$ (Fig. 1a). The percentage of leachable fraction in the extract of Hetron-treated samples was relatively higher (by about 3\%) when compared with Polymal-treated samples. The percentage of leachable fraction in Hetron treated samples was $11.8-17.5 \%$ for $\mathrm{Ba}, 6.2-10.6 \%$ for $\mathrm{Cr}, 8.2-15 \%$ for $\mathrm{Zn}, 5.9-10.2 \%$ for $\mathrm{Pb}, 6.0-10.4 \%$ for $\mathrm{Cu}$, and $4.3-8.2 \%$ for $\mathrm{Fe}$ (Fig. 1b). The leaching was reduced by 91.4-84.7\% for Ba, $96.1-91.8 \%$ for $\mathrm{Cr}, 92.8-87.8 \%$ for $\mathrm{Zn}, 94.4-90.5 \%$ for $\mathrm{Pb}$, and $95.8-93.1 \%$ for Fe. Similarly, Hetron also reduced the leaching of all the heavy metals, but about 3\% less than that exhibited by Polymal.

\section{Effect of final pH of TCLP extract on metal leaching}

The leaching of some metals relies heavily on $\mathrm{pH}$ control. Some heavy metals, such as $\mathrm{Cr}, \mathrm{Pb}, \mathrm{Zn}, \mathrm{Cu}$, and $\mathrm{Fe}$, exhibit amphoteric behavior and have higher solubility at both high and low pH (Conner, 1990). However, polymeric resin solidification, unlike cement-based solidification, gave very minimal difference in $\mathrm{pH}$ between the initial and final extract. The $\mathrm{pH}$ of the initial extract was in the range of 4.90-4.93, however, the $\mathrm{pH}$ of the final extract ranged between 5.08-5.16 and 5.15-5.19 for Polymal- and Hetron-treated samples, respectively. Thus, there is little or no apparent relationship between $\mathrm{pH}$ and the percentage of leachable fraction of heavy metals. For Polymal treated samples, the percentage of leachable fraction increased as the resin loading decreased, while the final extract $\mathrm{pH}$ also increased. Similar trends were

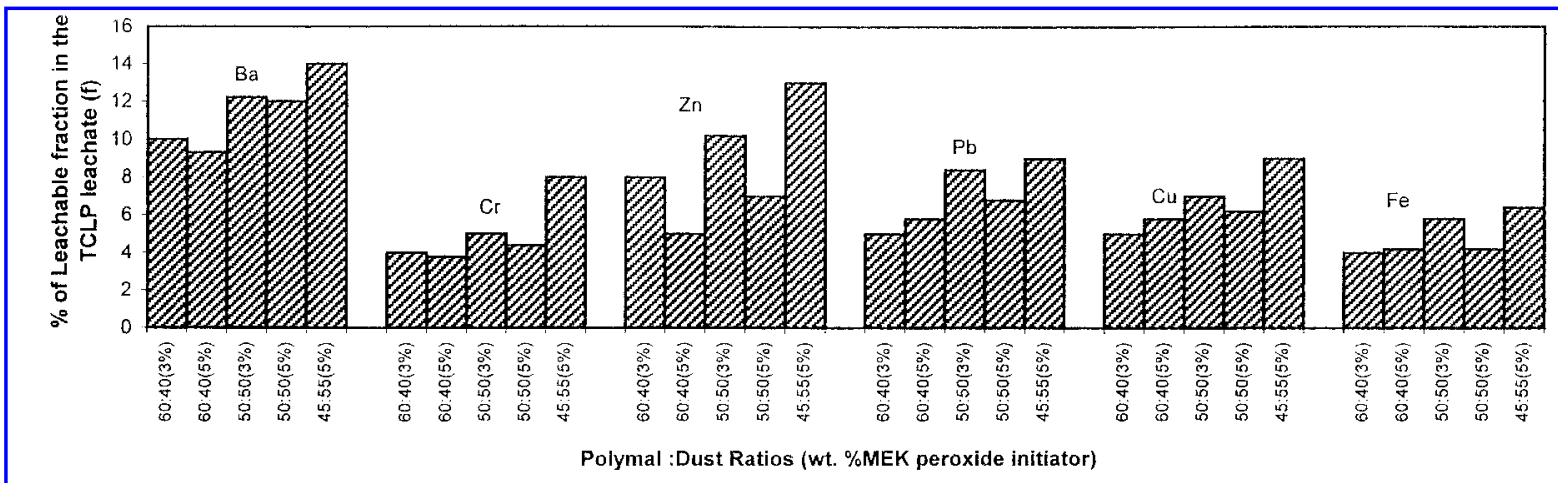

(a)

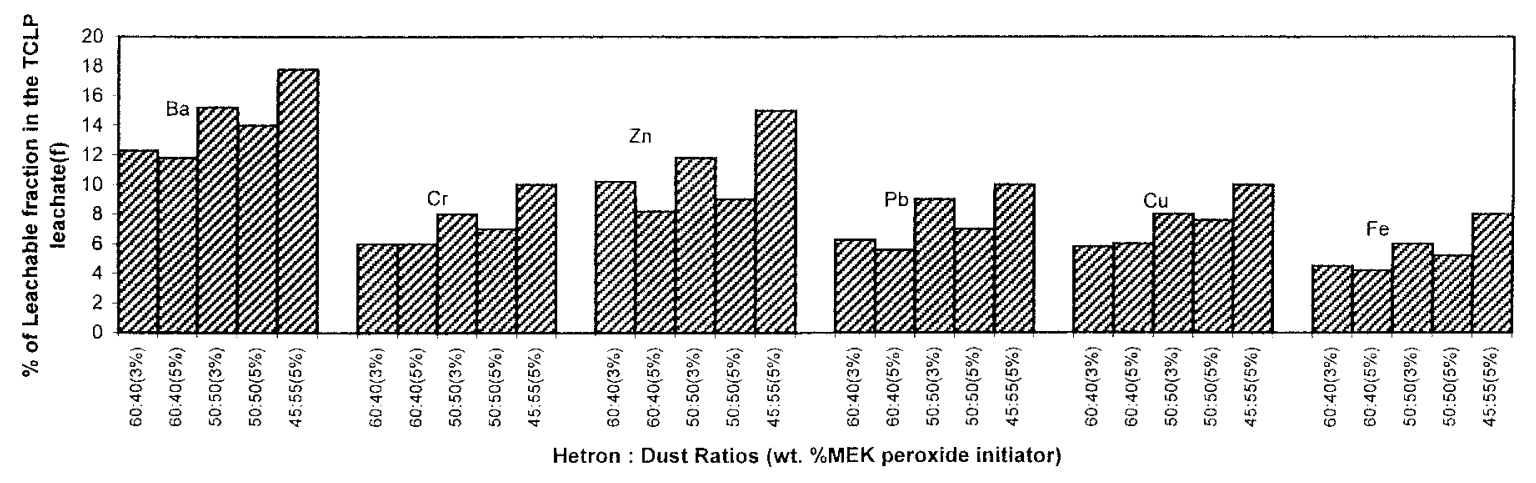

(b)

Figure 1. Percentage of leachable fraction of the heavy metals in the TCLP leachate of the (a) Polymal- and (b) Hetron-treated samples compared to the untreated dust. 
observed for Hetron solidified samples except that the $\mathrm{pH}$ decreased at the $45 \%$ resin level.

\section{ANS 16.1 (modified) leach rate}

Based on the values of leach rate, $l(\mathrm{~cm} /$ day), for each metal, rapid loss of heavy metals was recorded on the first interval, probably due to surface wash off of the solidified specimens (DeGroot and Sloot, 1992). Only Zn, $\mathrm{Ba}$, and $\mathrm{Pb}$ were detected when the leachate was tested using ANS technique, whereas $\mathrm{Cr}, \mathrm{Cu}$, and $\mathrm{Fe}$ were below detection limit for all the ratios investigated (Figs. $2 a$ and $b$ ). The leach rate of all the three metals decreased over the 28-day leaching period for both Polymal and Hetron. All the metals leached were below EQA limit, showing that these resins retained the metals quite effectively. Leach rate of $\mathrm{Zn}$ was the highest for both resins, followed by $\mathrm{Ba}$, which showed a relatively constant, average leaching rate of $0.001 \mathrm{~cm} /$ day. The leaching of $\mathrm{Pb}$ only occurred after the second interval and decreased during the subsequent intervals (Fig. 2a and 2b).

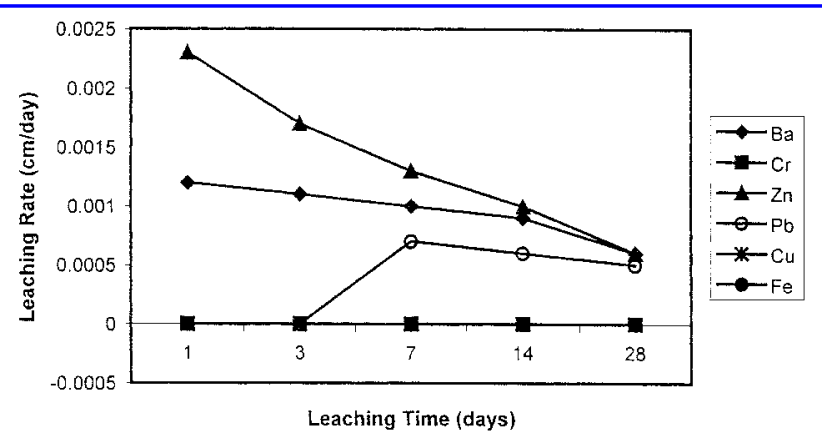

(a)

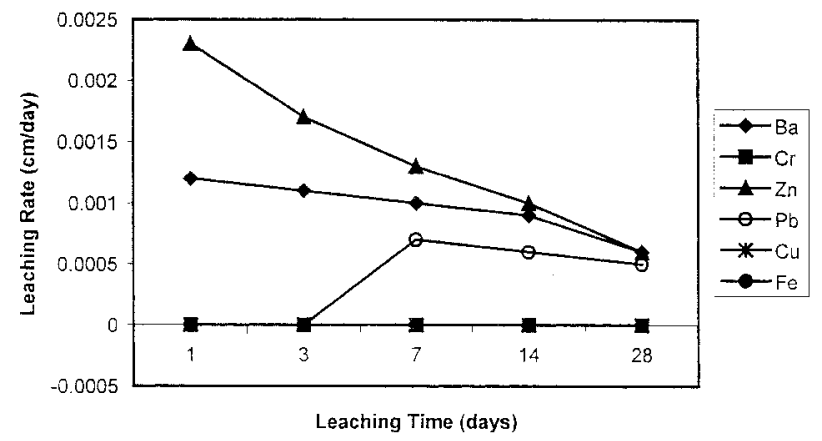

(b)

Figure 2. Leach rate of the heavy metals in the (a) Polymaland (b) Hetron-treated samples, at a resin:dust ratio of $60: 40$ with 5\% MEK peroxide initiator.

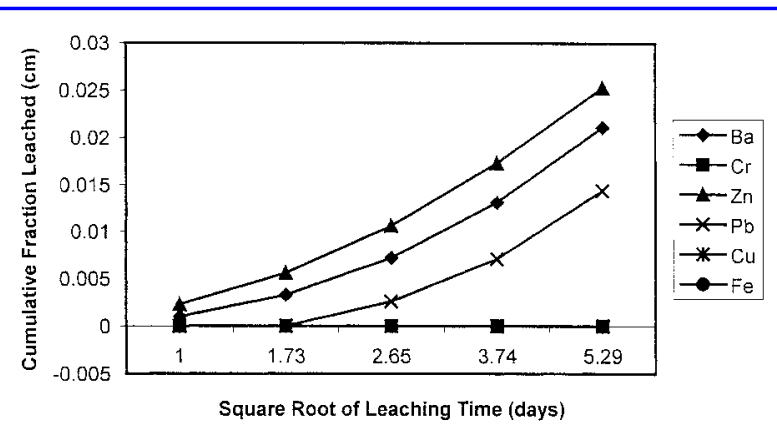

(a)

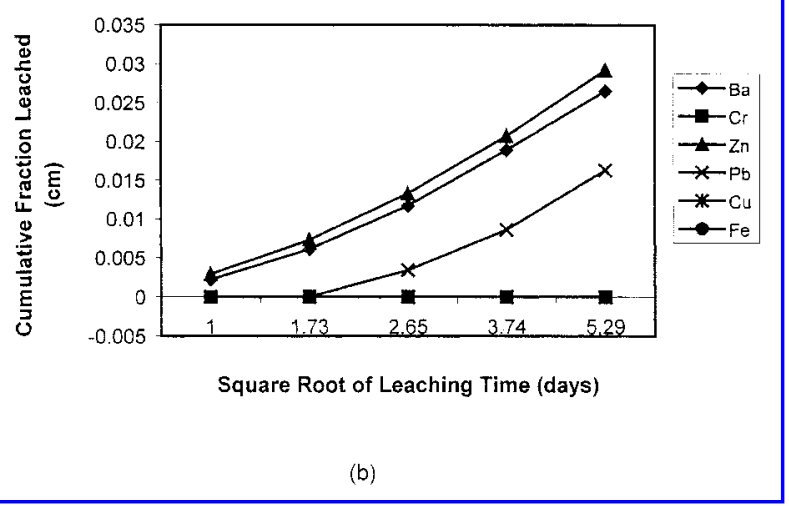

Figure 3. Cumulative Fraction Leached of the heavy metals in the (a) Polymal- and (b) Hetron-treated samples, at resin:dust ratio of 60:40 with 5\% MEK peroxide initiator.

\section{Cumulative fraction leached (CFL)}

Cumulative Fraction Leached was calculated using Equation (2). These are shown graphically in Fig. 3a (Polymal) and Fig. 3b (Hetron). The heavy metals leached $(\mathrm{Zn}, \mathrm{Ba}$, and $\mathrm{Pb})$ are seen to follow a diffusioncontrolled mechanism, because the CFL is almost linearly related to the square root of the leaching time (Figs. $3 \mathrm{a}$ and $\mathrm{b}$ ). For both resins, the CFL was the highest for $\mathrm{Zn}$, followed by $\mathrm{Ba}$ and $\mathrm{Pb}$, but decreasing as the brake lining dust loading increased. Hetron treatment gave slightly higher CFL values at all resin loadings. The maximum CFL for $\mathrm{Zn}$ was at $0.031 \mathrm{~cm}$ (at $60 \%$ Hetron). The straight-line relationship between the CFL and the square root of the leaching time is also evident here.

\section{Leachability Index $\left(\mathrm{L}_{\mathrm{i}}\right)$}

The effective diffusivity $\left(D_{i}\right)$ and Leachability Index $\left(L_{i}\right)$ for $\mathrm{Zn}$ were calculated according to Equations (3) and (5).

The Leachability Indices of the three heavy metals ( $\mathrm{Zn}$, $\mathrm{Ba}$, and $\mathrm{Pb}$ ) obtained in this study (ANS 16.1 (modified)) 


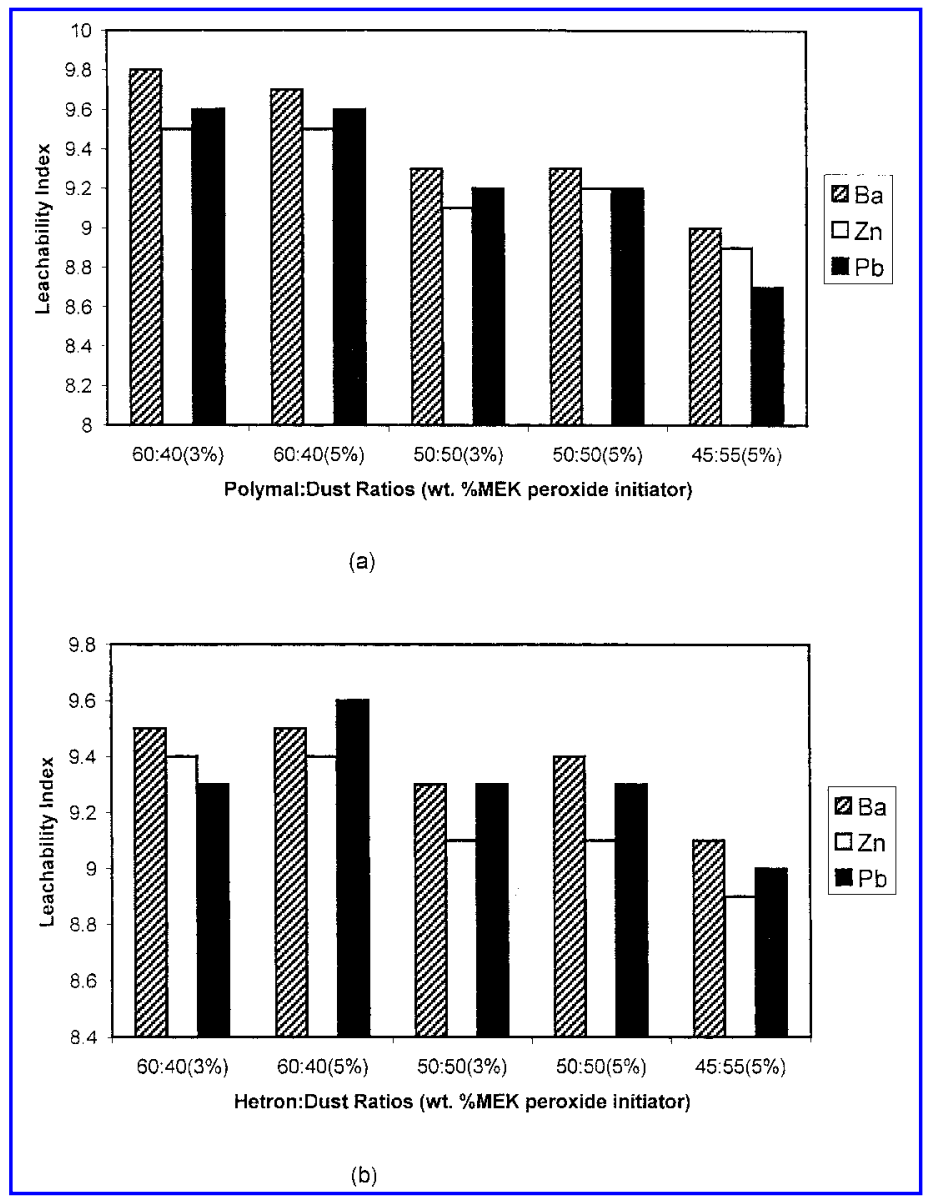

Figure 4. Leachability Index for (a) Polymal- and (b) Hetron-treated samples, at various resin:dust ratios and with 3 and $5 \%$ MEK peroxide initiator.

are summarized in Fig. 4. Polymal treated matrix gave $L_{i}$ values between 9 and 10, whereas Hetron gave $L_{i}$ values between 9 and 9.8 , and thus, the $L_{i}$ values obtained for both the resins used were higher than 6 , the stipulated guidance value (Morgan and Bostick, 1992). Hence,
Polymal and Hetron have effectively retained the heavy metals in the solidified matrix, although Polymal seems to perform slightly better than Hetron. Also, it is apparent there is no appreciable relationship between the amount of MEK Peroxide initiator and the leaching rate.

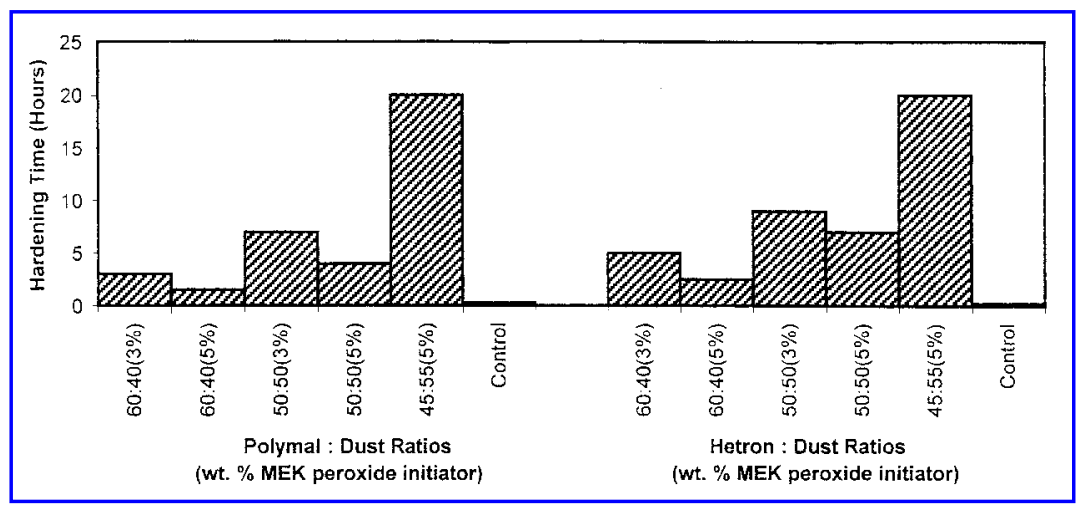

Figure 5. Hardening times of Polymal- and Hetron-treated brake lining dust. The resins were treated with 3 and 5\% MEK peroxide initiator. 


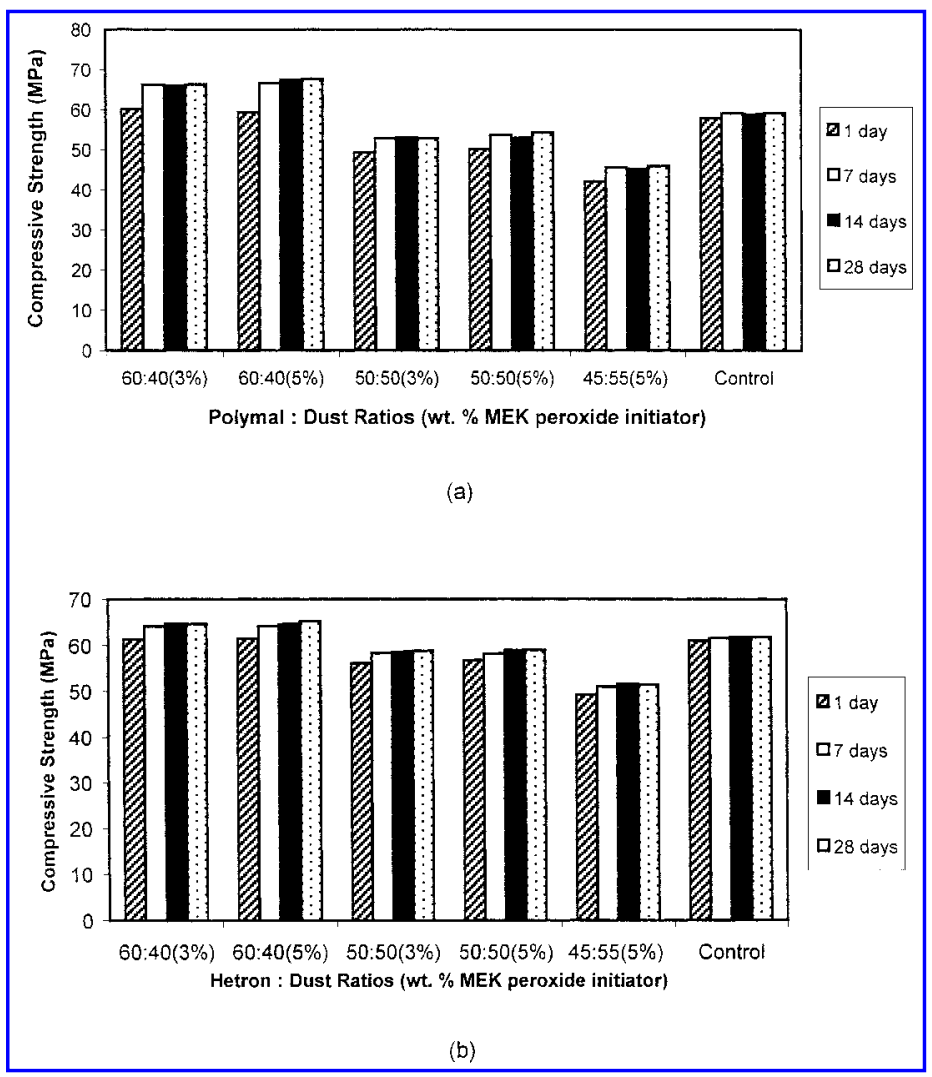

Figure 6. Compressive strength of the solidified waste after 1, 7, 14, and 28 days of solidification using (a) Polymal and (b) Hetron resins at different resin:dust ratios and with 3 and 5\% MEK peroxide initiator.

\section{Hardening time}

Polymeric resin solidification took 1.5 to $12 \mathrm{~h}$, whereas cement-based binding took about 30-96 h (Fig. 5). The control samples (i.e., the ones without the brake lining dust) of both polymeric resins hardened immediately af-

ter mixing in the MEK Peroxide initiator. The higher quantity of initiator $(5 \%)$ shortened the hardening time compared to the $3 \%$ case. The hardening time also increased with the increased loading of brake lining dust.

Table 3. Standards guidance for solidified waste form.

\begin{tabular}{lll}
\hline Properties & \multicolumn{1}{c}{ Test Methods } & Criteria \\
\hline Leachability & ANS 16.1 & Leachability Index $\geq 6$ \\
Compressive strength & ASTM C 39 or D 1074 & $414 \mathrm{kpa}(60 \mathrm{psi})$ \\
Radiation stability & See $1983 \mathrm{TP}$ & $414 \mathrm{kPa}$ compressive strength after $10 \mathrm{E} \pm 8$ rads \\
Biodegradation & ASTM G 21 and G 22 & No growth and compressive strength $>414 \mathrm{kPa}$ \\
Immersion & See $1938 \mathrm{TP}$ & $414 \mathrm{kPa}$ compressive strength after 90 days \\
Thermal cycling & ASTM B 553 & $414 \mathrm{kPa}$ compressive strength after 30 cycles \\
\hline
\end{tabular}

a The 1983 Branch technical Position (TP) paper calls for a minimum compressive strength of $345 \mathrm{kPa}$ (50 psi). This has been raised to $414 \mathrm{kPa}(60 \mathrm{psi}$ ) to accommodate an increased maximum burial depth at Hanford of $55 \mathrm{ft}$ (from $45 \mathrm{ft}$ ) as defined by the U.S. Nuclear Regulatory Commission publication.

bThe 1983 Branch technical Position (TP) paper calls for a multistep procedure for biodegradation testing: if observed culture growth rated "greater than 1" is observed following a repeated ASTM G 21 test, or any growth is observed following a repeated test of ASTM G22 test, longer term testing for (at least 6 months) is called for using the Bartha-Pramer method. From this test, a total weight loss extrapolated for full size waste forms to 300 years should produce less than a $10 \%$ loss of total carbon in the sample.

Source: Morgan and Bostick, 1992; Stegemann and Cote, 1992. 


\section{Compressive strength}

Polymeric resin solidification exhibited relatively consistent compressive strength, between 53 to $68 \mathrm{MPa}$ (Fig. 6). Generally, higher compressive strengths were observed for Hetron treated samples and the control, except for $60 \%$ resin loading, where Polymal-treated samples showed higher compressive strength of 60-67 MPa. The controls of both types of resins (cubes of resins without addition of dust) showed relatively lower compressive strength compared to the $60 \%$ resin loadings. Probably the presence of lining dust acted as a filler and enhanced the compressive strength of the solidified forms. However, the compressive strength decreased as the lining dust was increased from 40 to $55 \%$. The compressive strengths achieved with the polymeric resins were, however, much higher than the standard guidance limit for solidified waste form (Table 3) which is at $414 \mathrm{kPa}$.

\section{Cost evaluation}

Under the current local waste management practice, the brake lining dust is packed in double-layered highdensity polyethylene (HDPE) bags and placed in 200-L metal drums. The drums are next sealed, labeled, and disposed of at one of Malaysia's secure landfills at the Bukit Nanas Integrated Waste Management Center. Thus, as can be seen, there is currently no special treatment process followed for the dust except in terms of secure packaging. The hauling and disposal of these drums (300 metric tons per annum) at this secure landfill is a low RM283,000 (US\$75,000) per annum or US $\$ 0.25$ per $\mathrm{kg}$ of waste; however, no qualifications are placed on the long-term leach stability of the constituents present in the dust through this disposal procedure. If one now chooses the next level of option for the treatment of these 300 tons of fines, namely a cement solidification/stabilization option (Chan et al., 2000b) with a 50:50 ratio of waste: cement, the cost increases to a modest RM397,200 (US $\$ 104,526$ ) or US $\$ 0.33$ per $\mathrm{kg}$ of waste. If, in addition, an additive such as activated carbon is incorporated into the cement matrix, the cost rises to RM 571,200 (US $\$ 150,316$ ) at US $\$ 0.50$ per $\mathrm{kg}$ of waste. In these cost estimates, only the binder costs (cement at RM0.20 per $\mathrm{kg}$, activated carbon at RM6.0 per $\mathrm{kg}$ ) and waste hauling and disposal costs are included; no allowance has been made for the processing costs, which would normally include capital equipment and operating costs such as utilities, labor, and maintenance. Moving on to the Polymal and Hetron binders, these resins cost RM16.0 and RM18.5 per $\mathrm{kg}$, respectively; the corresponding total costs, using a basis similar to the cement 50:50 binder, are prohibitively high at RM5.3MM (US\$1.4MM) and RM6.1MM (US\$1.6MM), respectively, which works out to US $\$ 5.26$ and US $\$ 4.70$ per $\mathrm{kg}$ of waste.. It should, however, be borne in mind the various attractive features leading to the superiority of the resin $\mathrm{S} / \mathrm{S}$ option. In a recent report, Biyani et al. (2000) have carried out a comprehensive cost analysis for the S/S of sodium nitrate saltcontaining low-level radioactive waste (dry bulk specific gravity 0.7 ) for the U.S. market. Their conclusions are an attractive $\$ 11.50$ per $\mathrm{kg}$ of waste for the resin $\mathrm{S} / \mathrm{S}$ case, while for the cement case it is substantially higher at $\$ 16.37$ per kg of waste, both of these being inclusive of labor costs at US\$5.12 and US\$8.97 per $\mathrm{kg}$, respectively.

\section{CONCLUSIONS}

The Polymal S/S process gave better performance for heavy metal retention capacity, whereas the Hetron case exhibited higher compressive strength; both resins, however, retained the metals well within the stipulated limits. Based on current regulatory requirements in Malaysia, the resin S/S option is not an economically viable one, although it may merit consideration elsewhere overseas.

\section{ACKNOWLEDGEMENT}

We are grateful to Ms. P. Jayanthi and Mr. Greg Simpson from Don Brake (Malaysia) for their advice and suggestion, and for allowing us to conduct part of the research in their manufacturing facility. One of the authors (R.M.) wishes to thank the USIA Fulbright Scholar Program and the Malaysian-American Commission on Educational Exchange (MACEE) for a Fulbright Visiting Professor Award at the University of Malaya that facilitated this author's participation in the research. The project was funded by a PJP grant from the University of Malaya.

\section{REFERENCES}

ALBINO, V., CIOFFI, R., DE VITO, B., and SANTORO, L. (1996). Evaluation of solid waste stabilization processes by means of leaching tests. Environ. Technol. 17, 309-315.

AMERICAN NUCLEAR SOCIETY (ANS). (1986). Measurement of the Leachability of Solidified Low-Level Radioactive Wastes by a Short-Term Test Procedure, (ANSI/ANS-16-1). LaGrange Park, IL: Am. Nuc. Soc., p. 35.

AMERICAN SOCIETY FOR TESTING AND MATERIALS (ASTM). (1992). Standard test method for compressive strength of hydraulic cement mortars, C109/c 109M-95, Annual Book of ASTM Standard, 04.01, pp. 68-72. 
BIYANI, R.K., AGAMUTHU, P., and MAHALINGAM, R. (2000). Solidification/stabilization technologies-Polymer microencapsulation. In C.H. Oh, Ed. Handbook on Mixed Waste Treatment Technologies. Boca Raton, FL: CRC Press LLC (in press).

BRESLIN, V.T., and TISDELL, S.E. (1994). Thermoplastic stabilization of MSW combustor ash. J. Environ. Eng. 120, 154-168.

BRODERSEN, K., HJEMAL, O., and MORTENSEN, S. (1992). Cement conditioning of waste materials and polluted soils using the GEODUR process. In T.M. Gillian and C.C. Wiles, Eds. SolidificationStabilization of Hazardous, Radioactive and Mixed Wastes, ASTM STP 1123. Philadelphia, PA: American Society for Testing and Materials, pp. 320-337.

CHAN, Y.M., AGAMUTHU, P., and MAHALINGAM, R. (2000a). Asbestos waste audit and recycling in an automobile brake manufacturing facility. J. Chem. Technol. Biotechnol. (accepted).

CHAN, Y.M., AGAMUTHU, P., and MAHALINGAM, R. (2000b). Solidification and stabilization of asbestos waste from an automobile brake manufacturing facility using cement. J. Hazardous Materials (in press).

CONNER, J.R. (1990). Chemical Fixation and Solidification of Hazardous Waste. New York: Van Nostrand Reinhold, pp. 259-273, 351-364, and 454-464.

DE GROOT, G.J., and VAN DER SLOOT, H.A. (1992). Determination of leaching characteristics of waste materials leading to environmental product certification. In T.M. Gillian and C.C. Wiles, Eds. SolidificationStabilization of Hazardous, Radioactive and Mixed Wastes, ASTM STP 1123. Philadelphia, PA: American Society for Testing and Materials, pp. 149-170.

GRUBE, W.E. (1992). Physical and morphological measures of waste solidification effectiveness of environmental control technologies. In P.N. Cheremisinoff, Ed. Waste Minimization and Recycling. Houston, TX: Gulf Publishing Co., pp. 123-133.

KIM, H.Y., KIM, K.H., PARK, H.H., and SUH, I.S. (1992). Solidification of dried borate waste with polyester. In T.M. Gilliam and C.C. Wiles, Eds. SolidificationStabilization of Hazardous, Radioactive and Mixed Wastes, ASTM STP 1123. Philadelphia, PA: American Society for Testing and Materials, pp. 297-303.

LAGREGA, M.D., BUCKINGHAM, P.L., EVANS, P.L., and THE ENVIRONMENTAL RESOURCES MANAGEMENT GROUP. (1994). Hazardous Waste Management. New York: McGraw-Hill, pp. 641-703.

MANJUNATH, C., and CHEREMISINOFF, P.N. (1995). Asbestos abatement and removal techniques. In Encyclopedia of Environmental Control Technology: Pollution Reduction and Contaminant Control, vol. 6. Gulf Publishing Co., pp. $447-475$.
MEANS, J.L., SMITH, L.A., NEHRING, K.W., BRAUNING, S.E., GAVASKAR, A.R., SASS, B.M., WILES, C.C., and MASNI, C.I. (1995). The Application of SolidificationStabilization to Waste Materials. Cincinnati, OH: Lewis Publishers, p. 334.

MORGAN, I.L., and BOSTICK, W.D. (1992). Performance testing of grout-based waste forms for the solidification of anion exchange resins. In T.M. Gilliam and C.C. Wiles, Eds. SolidificationStabilization of Hazardous, Radioactive and Mixed Wastes, ASTM STP 1123. Philadelphia, PA: American Society for Testing and Materials, pp. 133-145.

POWELL, M.R., and MAHALINGAM, R. (1992a). Continuous solidification/stabilization processing of hazardous waste through polymeric microencapsulation. Indust. Eng. Chem. Res. 31, 543-549.

POWELL, M.R., and MAHALINGAM, R. (1992b). Leach studies on hazardous waste monoliths from continuous solidification/stabilization processing. Environ. Sci. Technol. 26, 507-511.

SHARMA, H.D., and LEWIS, S.P. (1994). Waste Containment System, Waste Stabilization and Landfills: Design and Evaluation. New York: John Wiley and Sons, Inc., p. 233.

STEGEMEN, J.A., and COTE, P.L. (1992). A proposed protocol for evaluation of solidified waste. In R.W. Piggot, Ed. Proceedings of Cement Industry Solutions to Waste Management, Calgary, CPCA, Toronto (Canada), pp. 1-12.

SUBRAMANIAN, R.V., and MAHALINGAM, R. (1979). Immobilization of hazardous residuals by polyester encapsulation. In R.B. Pojasek, Ed. Toxic and Hazardous Waste Disposal, Vol. 1. Ann Arbor, MI: Ann Arbor Science Publisher, pp. 247-295.

U.S. EPA, ENGINEERING BULLETIN. (1992). Solidification/Stabilization of Organics and Inorganics, EPA/540/S92/015. Cincinnati, OH: U.S. Environmental Protection Agency, Office of Research and Development.

U.S. EPA, ENGINEERING BULLETIN. (1997). Technology Alternatives for The Remediation of Soils Contaminated with As, $\mathrm{Cd}, \mathrm{Cr}, \mathrm{Hg}$ and $\mathrm{Pb}, \mathrm{EPA} / 540 / \mathrm{S}-97 / 50$. Cincinnati, $\mathrm{OH}$ : U.S. Environmental Protection Agency, Office of Emergency and Remedial Response.

U.S. EPA/ORIA. (1996). Process for Specific Low-Level Mixed Waste $(L L M W)$. Cincinnati, OH: Office of Remediation and Indoor Air (ORIA), U.S. Environmental Protection Agency.

U.S. EPA METHOD 1311. (1992). Toxicity Characteristics Leaching Procedure. Washington, DC: U.S. Environmental Protection Agency, Method 1311 (Reviewed).

WILES, C.C. (1989). Solidification/stabilization technology. In H.M. Freeman, Ed. Standard Handbook of Hazardous Waste Treatment and Disposal. New York: McGraw-Hill, Inc., pp. 7.85-7.101. 


\section{This article has been cited by:}

1. A. Faik, S. Guillot, J. Lambert, E. Véron, S. Ory, C. Bessada, P. Echegut, X. Py. 2011. Thermal storage material from inertized wastes: Evolution of structural and radiative properties with temperature. Solar Energy . [CrossRef]

2. V ROUBICEK, H RACLAVSKA, D JUCHELKOVA, P FILIP. 2007. Wear and environmental aspects of composite materials for automotive braking industry. Wear . [CrossRef] 